\title{
Growth of Hard Amorphous Ti-Al-Si-N Thin Films by Cathodic Arc Evaporation
}

\author{
Hanna Fager, J. M. Andersson, Mats Johansson, Magnus Odén and Lars Hultman
}

\section{Linköping University Post Print}

\section{Tweet}

N.B.: When citing this work, cite the original article.

Original Publication:

Hanna Fager, J. M. Andersson, Mats Johansson, Magnus Odén and Lars Hultman, Growth of Hard Amorphous Ti-Al-Si-N Thin Films by Cathodic Arc Evaporation, 2013, Surface \&amp; Coatings Technology, (235), 25, 376-385.

http://dx.doi.org/10.1016/j.surfcoat.2013.07.014

Copyright: Elsevier

\section{http://www.elsevier.com/}

Postprint available at: Linköping University Electronic Press

http://urn.kb.se/resolve?urn=urn:nbn:se:liu:diva-80199

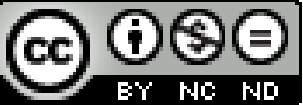




\title{
Growth of Hard Amorphous Ti-Al-Si-N Thin Films by Cathodic Arc Evaporation
}

\author{
H. Fager ${ }^{\mathrm{a}, *}$, J.M. Andersson ${ }^{\mathrm{b}}$, J. Luª, M.P. Johansson Jöesaar ${ }^{\mathrm{b}, \mathrm{c}}$, M. Odén ${ }^{\mathrm{c}}$, L. Hultman ${ }^{\mathrm{a}}$ \\ ${ }^{a}$ Thin Film Physics Division, Department of Physics, Chemistry, and Biology (IFM), Linköping University, SE-581 83 Linköping, Sweden \\ ${ }^{b}$ Seco Tools AB, SE-737 82 Fagersta, Sweden \\ ${ }^{c}$ Nanostructured Materials, Department of Physics, Chemistry, and Biology (IFM), Linköping University, SE-581 83 Linköping, Sweden
}

\begin{abstract}
$\mathrm{Ti}_{1-x-y} \mathrm{Al}_{x} \mathrm{Si}_{y} \mathrm{~N}_{z}(0.02 \leq \mathrm{x} \leq 0.46,0.02 \leq \mathrm{y} \leq 0.28$, and $1.08 \leq \mathrm{z} \leq 1.29)$ thin films were grown on cemented carbide substrates in an industrial scale cathodic arc evaporation system using Ti-Al, Ti-Si, and Ti-Al-Si cathodes in a $\mathrm{N}_{2}$ atmosphere. The microstructure of the as-deposited films changes from nanocrystalline to amorphous by addition of $\mathrm{Al}$ and $\mathrm{Si}$ to TiN. Upon incorporation of 12 at $\% \mathrm{Si}$ and 18 at\% $\mathrm{Al}$, the films assume an $\mathrm{x}$-ray amorphous state. Post-deposition anneals show that the films are thermally stable up to $900^{\circ} \mathrm{C}$. The films exhibit age hardening up to $1100{ }^{\circ} \mathrm{C}$ with an increase in hardness from $19.4 \mathrm{GPa}$ for as-deposited films to $27.1 \mathrm{GPa}$ at $1100{ }^{\circ} \mathrm{C}$. At $1100^{\circ} \mathrm{C}$ out-diffusion of Co and $\mathrm{W}$ from the substrate occur, and the films crystallize into c-TiN and h-AlN.
\end{abstract}

Keywords: PVD, Transmission electron microscopy (TEM), Thin films, Amorphous, TiAlSiN, Hardness

\section{Introduction}

Transition metal nitride materials such as polycrystalline Ti-Al-N and nanocrystalline $\mathrm{TiN} / \mathrm{Si}_{3} \mathrm{~N}_{4}$ composites are attractive for many applications, e.g., as protective coatings on cutting tools and as decorative thin films, due to properties such as high hardness [1], mechanical wear resistance [2], high thermal stability [3, 4], and good oxidation resistance [5-8]. In contrast, very little is known for the corresponding amorphous nitrides. Amorphous nitrides, e.g., of the TiNAlN-Si $\mathrm{N}_{4}$ system, would not be impaired by the relative weakness of grain boundaries. Grain boundaries also act as diffusion paths between substrate and work material or atmosphere. Thus, dense amorphous nitride films could lead to improved performance compared to crystalline ones.

In general, the formation of amorphous phases is promoted in alloy systems where (1) the heat of mixing is strongly negative, hence in systems with strong tendency for compound formation, (2) there is a large difference $(>10 \%)$ in atomic size, and (3) deep eutectic points exist $[9,10]$. Also, $\mathrm{N}$ and metalloids as $\mathrm{Si}$ and $\mathrm{B}$, are known to stabilize amorphous compounds [11, 12].

With basis in the useful chemical and thermal properties of the respective parent compounds, we propose the

\footnotetext{
${ }^{*}$ Corresponding author

Email address: hanfa@ifm.liu.se (H. Fager)
}

Ti-Al-Si-N system for a study on possible amorphous structures in thin films.

In previous studies on transition metal nitride based systems where Si has been added to promote formation of amorphous structure, Sun et al. [13] showed that amorphous Ti-Si-N is thermally stable up to $850{ }^{\circ} \mathrm{C}$, which was confirmed by Blanquet et al. [14]. For the $\mathrm{Zr}-\mathrm{Si}-\mathrm{N}$ system, $\mathrm{ZrN}_{x}(\mathrm{x}>1)$ is known to be ultrafine grained or even amorphous [15], and Daniel et al. showed that x-ray amorphous $\mathrm{Zr}-\mathrm{Si}-\mathrm{N}$ thin films, with Si content $\geq 25$ at $\%$ are thermally stable against crystallization during $30 \mathrm{~min}$ vacuum anneals at temperatures up to $800{ }^{\circ} \mathrm{C}$ [16]. The films were thermally stable to even higher temperatures, $1450{ }^{\circ} \mathrm{C}$, if removed from their $\mathrm{Si}(001)$ substrates.

Also for $\mathrm{Zr}-\mathrm{Si}-\mathrm{N}$ films, Musil et al. reported on high hardness $(\sim 30 \mathrm{GPa})$ and good oxidation resistance in flowing air up to $1300^{\circ} \mathrm{C}$ for films containing $25-43$ at $\%$ $\mathrm{Si}$ [11]. The high thermal stability, in combination with high hardness, low compressive stresses $(\approx-1 \mathrm{GPa})$, and good oxidation resistance make the $\mathrm{x}$-ray amorphous $\mathrm{Zr}$-Si-N films suitable for wear-protective coatings, and for use in high-temperature applications such as highspeed cutting and thermal protection of surfaces.

Flink et al. [17] reported on arc evaporated $\left(\mathrm{Ti}_{0.33} \mathrm{Al}_{0.67}\right)_{1-x} \mathrm{Si}_{x} \mathrm{~N}(0 \leq \mathrm{x} \leq 0.29)$ thin films, where films with $\mathrm{Si}$ concentration $\mathrm{x} \geq 0.17$ exhibited an $\mathrm{x}$-ray amorphous structure. Increase of $\mathrm{Al}$ concentrations above 
$60-70$ at $\%$ in arc evaporated films favors a phase mixture of cubic TiN and hexagonal AlN. Addition of Si above 10 at $\%$ to Ti-Si-N induces the formation of amorphous $\mathrm{Si}_{3} \mathrm{~N}_{4}$ [18, 19], beacuase of tetrahedral bonding coordination that severly distorts the cubic TiN lattice.

For the few studies reporting on amorphous transition metal nitrides mentioned above, the structure was assessed mainly by x-ray diffraction. That technique, however, is insensitive to crystallites smaller than a few $\mathrm{nm}$ and to rule out the presence of grains other techniques such as electron diffraction are required. Here, we produce Ti-Al-Si-N films by arc-evaporation. The films are both x-ray amorphous and essentially electrondiffraction amorphous, limiting the possible crystallite size to $\sim 1 \mathrm{~nm}$. The amorphous structure is explained by the difference in atomic radii $\left(\mathrm{r}_{N}=0.065 \mathrm{~nm}\right.$, $\mathrm{r}_{S i}=0.110 \mathrm{~nm}, \mathrm{r}_{A l}=0.125 \mathrm{~nm}$, and $\mathrm{r}_{T i}=0.140 \mathrm{~nm} \mathrm{[20])}$ and that the equilibrium parent compounds have different bond coordination and preferred crystal structure. This, in combination with low-temperature kineticallylimited growth and high deposition rates, which do not allow adatoms sufficient time to find minimum energy sites, is expected to hinder crystallization.

The films were annealed up to $1100{ }^{\circ} \mathrm{C}$, and proven to be thermally stable up to $900{ }^{\circ} \mathrm{C}$, where a small number of nanocrystals form. The films exhibit age hardening up to $1100^{\circ} \mathrm{C}$. At $1100^{\circ} \mathrm{C}, \mathrm{Co}$ and $\mathrm{W}$ from the substrate diffuse into the film and c-TiN and h-AlN crystallizes.

\section{Experimental procedures}

$\mathrm{Ti}_{1-x-y} \mathrm{Al}_{x} \mathrm{Si}_{y} \mathrm{~N}_{z}, \quad 0.02 \leq \mathrm{x} \leq 0.46, \quad 0.02 \leq \mathrm{y} \leq 0.28$, and $1.08 \leq \mathrm{z} \leq 1.29$ thin films were grown in an industrial scale arc evaporation system (Sulzer Metaplas MZR323). Three $63 \mathrm{~mm}$ diameter cathodes were aligned vertically, with compositions (top to bottom): $\mathrm{Ti}_{0.75} \mathrm{Si}_{0.25}, \mathrm{Ti}_{0.23} \mathrm{Al}_{0.47} \mathrm{Si}_{0.30}$, and $\mathrm{Ti}_{0.75} \mathrm{Al}_{0.25}$. This arrangement enabled variations in film compositions depending on the position of the substrates in relation to the cathodes. The cathodes were operated with an arc current of 75 A DC. Polished cemented carbide (WCCo) $12 \times 12 \times 4 \mathrm{~mm}^{3}$ were used as substrates.

Prior to deposition, all substrates were ultrasonically cleaned in a degreasing agent. The substrates were placed on a rotating cylinder in the center of the deposition chamber. A negative bias potential of $-30 \mathrm{~V}$ was applied. After initial degassing of the chamber at $\sim 400{ }^{\circ} \mathrm{C}$, and plasma etching of the substrates, the depositions were carried out at approximately $300{ }^{\circ} \mathrm{C}$. Nitrogen ( $99.995 \%$ purity) was introduced as the reactive gas at a total pressure of $4 \mathrm{~Pa}$. The base pressure was $\sim 10^{-3} \mathrm{~Pa}$ and the film thickness was in the range 0.8$3.1 \mu \mathrm{m}$.

Post-deposition anneals of samples were performed in a tube furnace in an $\mathrm{Ar}$ atmosphere at temperatures between $500{ }^{\circ} \mathrm{C}$ and $1100{ }^{\circ} \mathrm{C}$. The furnace was heated with a rate of $10{ }^{\circ} \mathrm{C} / \mathrm{min}$ to the selected temperature, and held constant for $2 \mathrm{~h}$. After annealing the samples were allowed to cool to room temperature in the Ar atmosphere.

For phase analysis and structural analysis, a Bruker AXS D8 Advance X-ray diffractometer with a line focus $\mathrm{Cu} \mathrm{K}_{\alpha}$ x-ray source was used. $\theta-2 \theta$ scans were conducted in the $2 \theta$ range from $20^{\circ}$ to $90^{\circ}$.

A PANalytical Empyrean X-ray diffractometer with a point focus $\mathrm{Cu} \mathrm{K}_{\alpha}$ X-ray source was used for residual stress measurements. The residual stress was calculated using the $\sin ^{2} \Psi$ method based on the $\mathrm{Ti}_{1-x-y} \mathrm{Al}_{x} \mathrm{Si}_{y} \mathrm{~N}_{z}$ 002 peak for as-deposited films with $1-x-y>0.34$. For all calculations, a Poisson's ratio ( $v$ ) of 0.22 and Young's modulus (E) of $450 \mathrm{GPa}$ were used, as were determined for TiN [21].

The chemical composition of the films was determined by energy dispersive x-ray spectroscopy (EDX) in a LEO1550 field emission gun scanning electron microscope (SEM) equipped with AZtec X-max EDS, operated at $20 \mathrm{kV}$. For the quantitative analysis, industrial standards were used, and ZAF correction was applied.

A FEI Tecnai G2 TF 20 UT microscope equipped with an EDX spectrometer operated at $200 \mathrm{kV}$ was used for transmission electron microscopy (TEM), scanning TEM (STEM), and energy dispersive x-ray spectroscopy (EDX) elemental mapping investigations. Cross sectional TEM samples were prepared by mechanical polishing and ion milling. For the STEM analysis, a high angle annular dark field detector (HAADF) was used, at a camera length of $190 \mathrm{~nm}$. We used discernible features at the edge of the sample during the tilting experiments to ensure that the same area was imaged for all tilt angles.

Hardness measurements were performed on polished tapered cross sections using a Hysitron TI-950 TriboIndenter equipped with a Berkovich $142.3^{\circ}$ diamond probe, calibrated using a fused silica standard. For each sample, a minimum of 25 indents were made at an indentation depth of $\sim 70 \mathrm{~nm}$, corresponding to a maximum applied load of $11 \mathrm{mN}$. The indentation procedure consisted of three steps: 1) loading to $\mathrm{P}_{\max }$ during $5 \mathrm{~s}$, 2) hold for $2 \mathrm{~s}$, and 3) unloading during $5 \mathrm{~s}$. The average hardness and its standard deviation were determined using the method described by Oliver and Pharr [22] by fitting $80 \%$ of the unloading curve. Elastic modulus 
Table 1: Elemental composition of the as-deposited films on WC-Co substrates as measured by EDX. The values have been normalized to 100 at $\%$.

\begin{tabular}{lrrrrc}
\hline Cathode & $\mathrm{Ti}($ at $\%)$ & $\mathrm{Al}($ at $\%)$ & $\mathrm{Si}($ at $\%)$ & $\mathrm{N}($ at\% $)$ & Composition \\
\hline $\mathrm{Ti}_{0.75} \mathrm{Si}_{0.25}$ & 33.0 & 0.9 & 9.8 & 56.3 & $\mathrm{Ti}_{0.76} \mathrm{Al}_{0.02} \mathrm{Si}_{0.22} \mathrm{~N}_{1.29}$ \\
& 28.1 & 6.0 & 11.3 & 54.7 & $\mathrm{Ti}_{0.62} \mathrm{Al}_{0.13} \mathrm{Si}_{0.25} \mathrm{~N}_{1.21}$ \\
$\mathrm{Ti}_{0.23} \mathrm{Al}_{0.47} \mathrm{Si}_{0.30}$ & 13.9 & 18.7 & 12.4 & 55.0 & $\mathrm{Ti}_{0.31} \mathrm{Al}_{0.41} \mathrm{Si}_{0.28} \mathrm{~N}_{1.22}$ \\
& 12.0 & 21.5 & 12.7 & 53.8 & $\mathrm{Ti}_{0.26} \mathrm{Al}_{0.46} \mathrm{Si}_{0.28} \mathrm{~N}_{1.17}$ \\
& 15.2 & 17.9 & 12.2 & 54.6 & $\mathrm{Ti}_{0.34} \mathrm{Al}_{0.39} \mathrm{Si}_{0.27} \mathrm{~N}_{1.20}$ \\
$\mathrm{Ti}_{0.75} \mathrm{Al}_{0.25}$ & 27.2 & 16.2 & 3.3 & 53.2 & $\mathrm{Ti}_{0.58} \mathrm{Al}_{0.35} \mathrm{Si}_{0.07} \mathrm{~N}_{1.14}$ \\
\hline
\end{tabular}

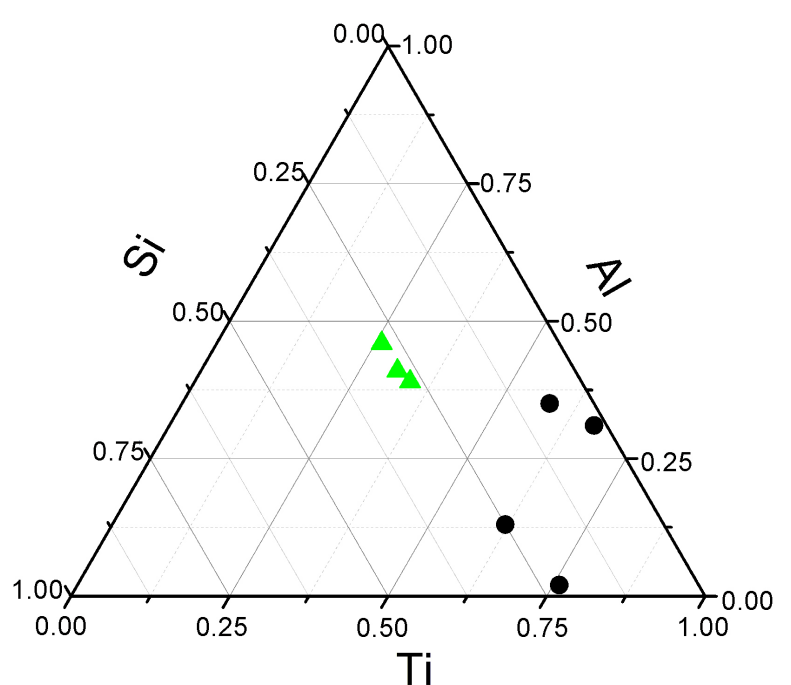

Figure 1: (Color online) Compositional diagram for $\mathrm{Ti}_{1-x-y} \mathrm{Al}_{x} \mathrm{Si}_{y} \mathrm{~N}_{z}$, $0.02 \leq \mathrm{x} \leq 0.46,0.02 \leq \mathrm{y} \leq 0.28$, and $1.08 \leq \mathrm{z} \leq 1.29$ thin films. Green triangles indicate amorphous film compositions.

values were calculated from the reduced modulus $\left(\mathrm{E}_{r}\right)$ using $v=0.22, v_{i}=0.07$, and $\mathrm{E}_{i}=1140 \mathrm{GPa}$. The indents were analyzed in AFM and it was found that the deformation mechanism was similar between the samples.

\section{Results and discussion}

The chemical composition of the as-deposited films determined by EDX is presented in Table 1 and schematically illustrated in Fig. 1. For Si-rich films, the nominal film compositions correspond well to the cathode composition. Some $\mathrm{Al}$ can be detected in these films due to plasma overlap with the $\mathrm{Ti}_{0.23} \mathrm{Al}_{0.47} \mathrm{Si}_{0.30}$ cathode. For films poor in Si, i.e. films facing the $\mathrm{Ti}_{0.75} \mathrm{Al}_{0.25}$ cathode, there is a few at\% elevated amount of $\mathrm{Al}$ compared to the nominal cathode composition due to the plasma overlap with the $\mathrm{Ti}_{0.23} \mathrm{Al}_{0.47} \mathrm{Si}_{0.30}$ cathode. All films are slightly overstochiometric in $\mathrm{N}$ $(1.08 \leq \mathrm{z} \leq 1.29)$ with respect to TiN. The trend is higher $\mathrm{N}$ concentration with higher $\mathrm{Si}$ concentration, as expected from the preferred 3:4 stoichiometry of tetrahedrally coordinated $\mathrm{Si}_{3} \mathrm{~N}_{4}$.

EDX is considered to be inaccurate for detection of lighter element, in our case nitrogen, carbon and oxygen. However, for magnetron sputtered Ti-Al-Si-N film we used a combination of elastic recoil detection analysis (ERDA) and EDX and found that EDX orderly overestimates $\mathrm{C}$. For $\mathrm{N}$ the difference in detected amount ranged from 0-2 at\%, and for $\mathrm{O} 0-1$ at $\%$. We also used ERDA for detection of impurities in arc evaporated TiAl-Si-N grown under similar conditions as in this study, which showed that the impurity levels ( $\mathrm{C}$ and $\mathrm{O})$ was lower than 1 at $\%$. The oxygen level increased from $\sim 0.1$ at $\%$ to $\sim 0.4$ at $\%$ with increasing Si content.

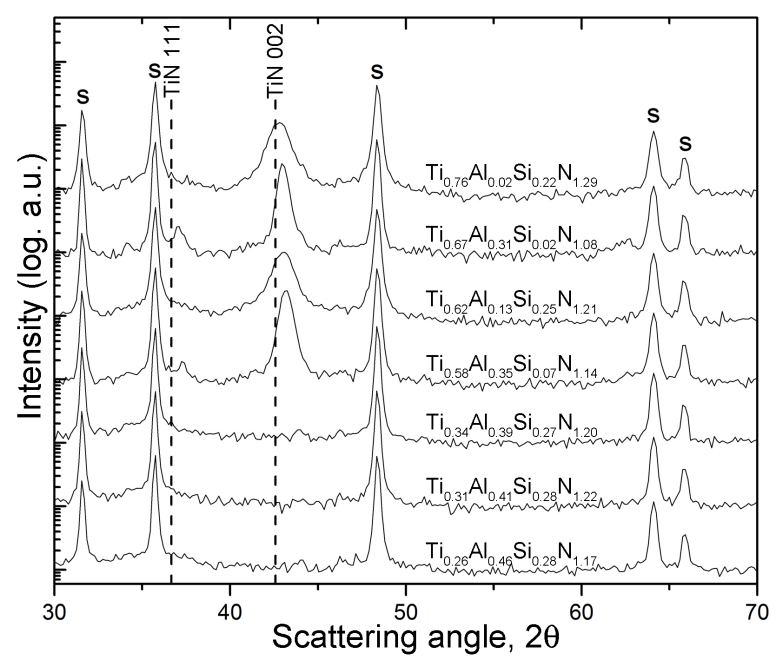

Figure 2: XRD patterns from as-deposited $\mathrm{Ti}_{1-x-y} \mathrm{Al}_{x} \mathrm{Si}_{y} \mathrm{~N}_{z}$ films with increasing Ti content, $0.26 \leq 1-\mathrm{x}-\mathrm{y} \leq 0.76$. Substrate peak are indicated by $\mathrm{S}$, and TiN with dashed lines.

Fig. 2 shows the XRD patterns from the as-deposited $\mathrm{Ti}_{1-x-y} \mathrm{Al}_{x} \mathrm{Si}_{y} \mathrm{~N}_{z}$ films. For a Ti content $1-\mathrm{x}-\mathrm{y} \leq 0.34$, the films are clearly $x$-ray amorphous. These films have 12- 


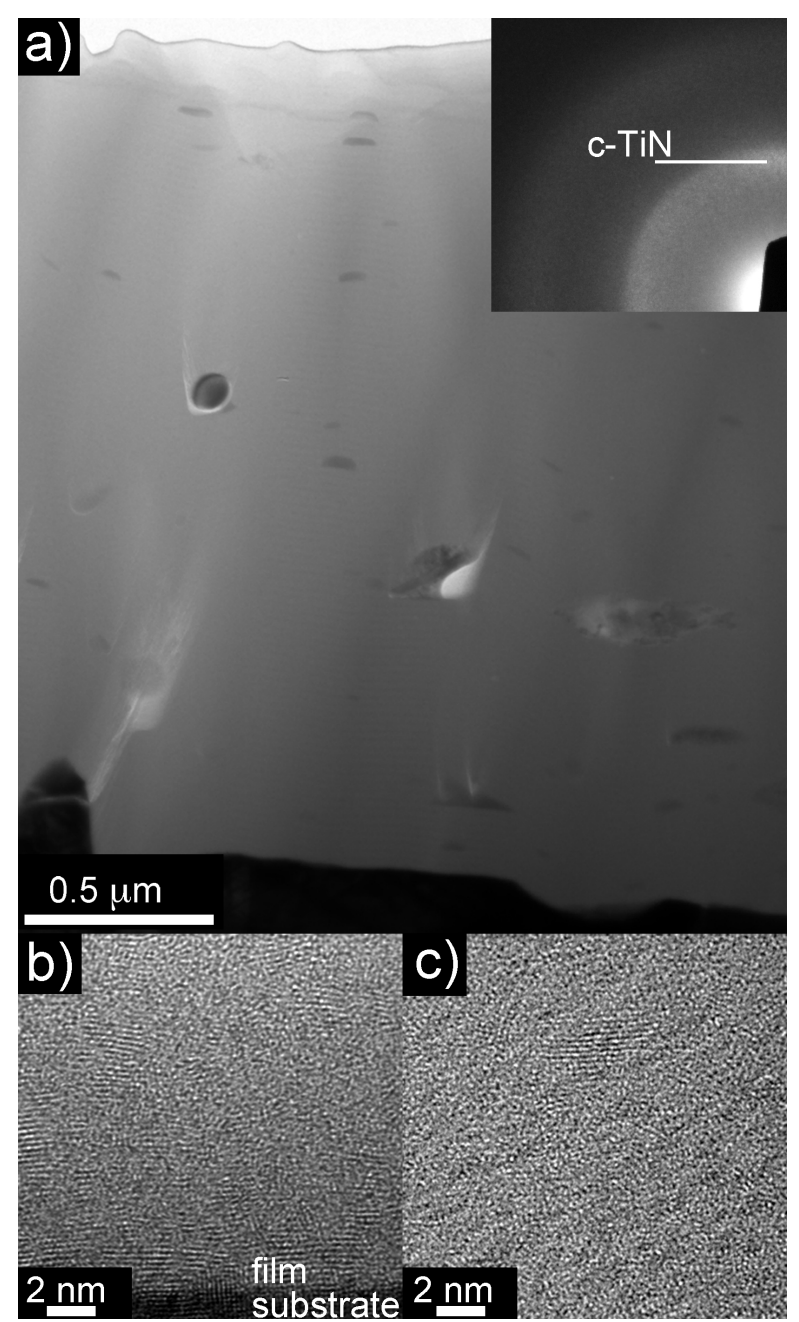

Figure 3: a) Cross-sectional TEM overview micrograph with selected area diffraction (SAED) pattern inset, b) HRTEM image from an area close to the substrate, and c) HRTEM image from an area $\sim 1 \mu \mathrm{m}$ up in an as-deposited $\mathrm{Ti}_{0.26} \mathrm{Al}_{0.46} \mathrm{Si}_{0.28} \mathrm{~N}_{1.17}$ film.

$13 \mathrm{at} \% \mathrm{Si}$ and a Al:Ti fraction in the range of 0.54-0.65.

It is well known that it is possible to maintain a cubic $\mathrm{Ti}_{1-x} \mathrm{Al}_{x} \mathrm{~N}$ solid solution with $\mathrm{x}$ up to $\sim 0.6-0.7$ [23] for films grown with cathodic arc evaporation. For higher $\mathrm{Al}$ concentrations the structure may decompose into cTiN and h-AlN during thin film deposition.

The effective solubility limit of $\mathrm{Si}$ in TiN is still unknown. While the phase diagram [24] states essentially zero solubility, a limit of $5-10$ at $\%$ has been reported for films grown under diffusion limited conditions [19, 25, 26]. Li et al. [19] suggested that addition of more than 10 at\% Si to TiN will lead to a supersaturation of the structure, forcing it to collapse into an amorphous state. However, Flink et al. showed that for
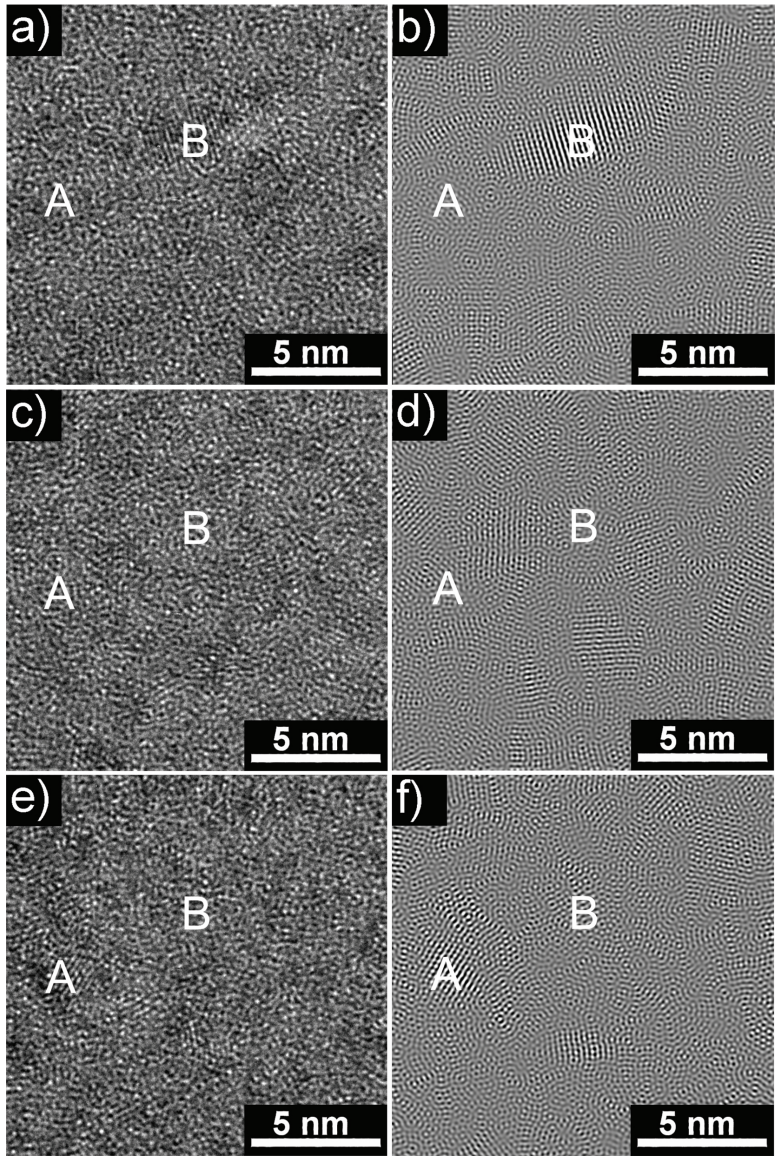

Figure 4: Bright field images of an as-deposited $\mathrm{Ti}_{0.26} \mathrm{Al}_{0.46} \mathrm{Si}_{0.28} \mathrm{~N}_{1.17}$ film and corresponding inverse Fourier transform images at three different tilt angles, $\alpha=0$ (a) and (b), $\alpha=10$ (c) and (d), and $\alpha=20$ (e) and (f), respectively.

arc evaporated films it was possible to add up to 5 at $\%$ Si keeping the solid solution intact, whereafter further addition caused Si to segregate to the grain boundaries during deposition, rendering a feather-like structure of the film [26]. Other studies $[3,27,28]$ also show that adding $7-10$ at\% Si to the TiN system by arc evaporation yield a nanocrystalline structure. However, the authors in [3] and [27], reported a reduced grain size with increasing Si content, which was indicated by broadening of XRD peaks. Also, Veprek et al. [29] report on reduced grain size with increasing Si concentration for Ti-Si-N thin films grown by plasma CVD. They report on addition of up to 14 at $\%$ Si without obtaining an amorphous structure.

For Ti-Si-N $(\mathrm{O})(\mathrm{O} / \mathrm{N}=0.2-0.5)$ thin films grown by cathodic arc evaporation Shalaeva et al. reported that films with 10 at\% Si had a nearly single-phase crystalline structure with minimum grains size of $1.5-2 \mathrm{~nm}$. 


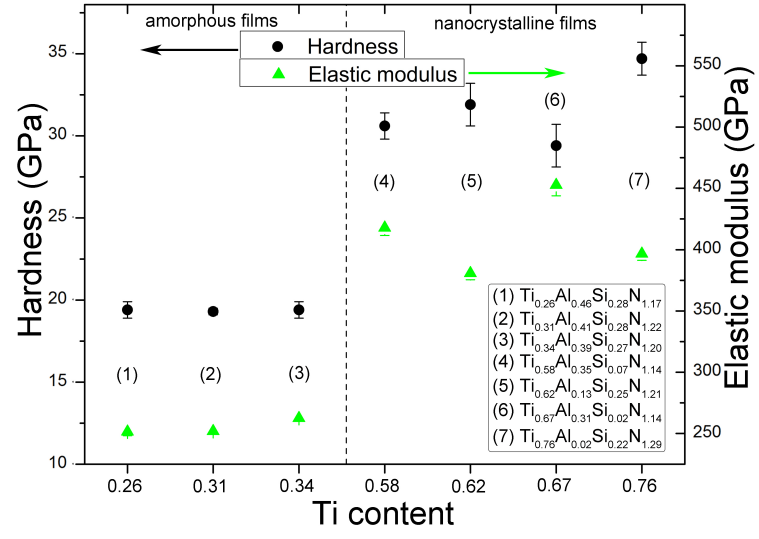

Figure 5: (Color online) Nanoindentation hardness (black circles) and elastic moduli (green triangles) of as-deposited $\mathrm{Ti}_{1-x-y} \mathrm{Al}_{x} \mathrm{Si}_{y} \mathrm{~N}_{z}$ films as a function of Ti content, $0.26 \leq 1-\mathrm{x}-\mathrm{y} \leq 0.76$.

When the Si concentration in the films was higher than 10-15 at\% with the constraint that the Ti concentration was no less than 45 at\%, a transition from ultradispersed $\mathrm{TiSiN}(\mathrm{O})$ solid solution to an amorphous alloy take place [30].

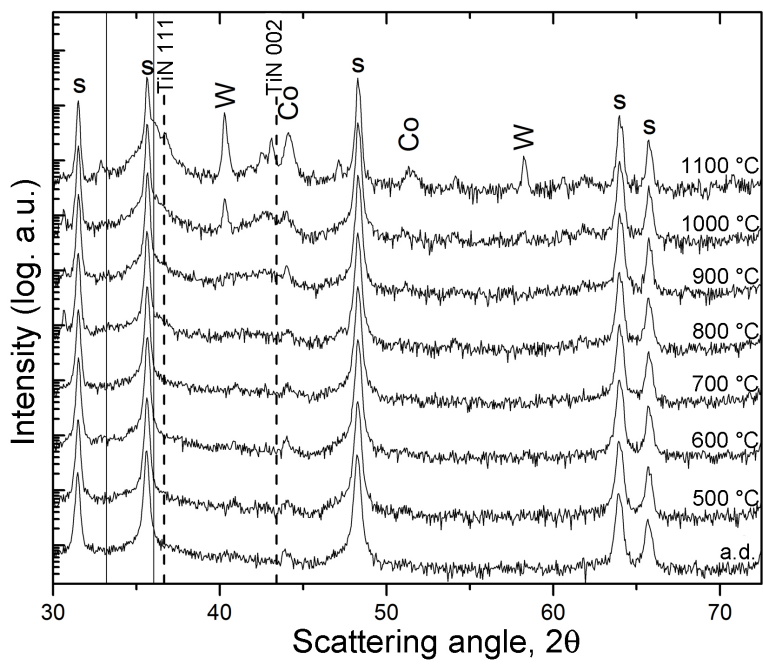

Figure 6: XRD patterns of annealed $\mathrm{Ti}_{0.26} \mathrm{Al}_{0.46} \mathrm{Si}_{0.28} \mathrm{~N}_{1.17}$ films, with respect to annealing temperature $500-1100{ }^{\circ} \mathrm{C}$. Substrate peaks are marked with $\mathrm{S}$, TiN with dashed lines, and AIN with solid lines.

The apparent amorphous state in films with 1$\mathrm{x}-\mathrm{y}<0.34$ is explained by the difference in size $\left(\mathrm{r}_{N}=0.065 \mathrm{~nm}, \mathrm{r}_{S i}=0.110 \mathrm{~nm}, \mathrm{r}_{A l}=0.125 \mathrm{~nm}\right.$, and $\mathrm{r}_{T i}=0.140 \mathrm{~nm}$ [20]) between the constituent elements, in combination with the different bond coordination, and preferred crystallographic structure of the parent compounds. Bonding in NaCl-structure transition metal nitrides such as TiN involves a combination of metallic, covalent, and ionic contributions [31], where the atoms are octahedrally coordinated and have a preferred 1:1 stoichiometry. AlN and SiN are both tetrahedrally coordinated; $\mathrm{Si}_{3} \mathrm{~N}_{4}$ with hexagonal, trigonal or amorphous structure, and AIN with hexagonal structure. Both consist of a mixture of covalent and ionic bonding [32]. We conclude that the amorphous state of the films in our case is due to a synergistic effect of adding both $\mathrm{Si}$ and Al to TiN which hinder crystalline growth.

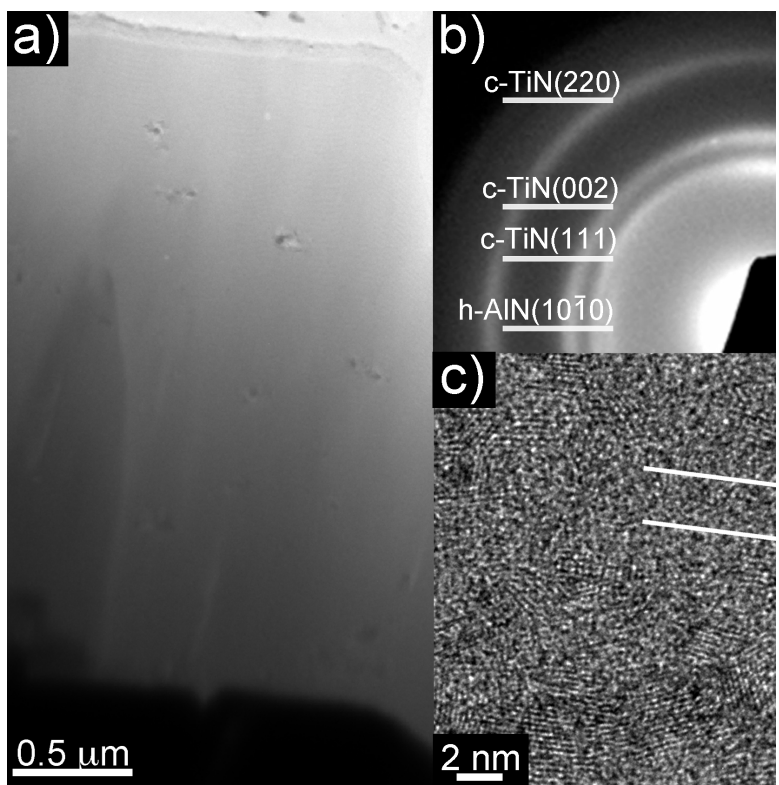

Figure 7: a) Cross-sectional TEM overview micrograph of a $\mathrm{Ti}_{0.26} \mathrm{Al}_{0.46} \mathrm{Si}_{0.28} \mathrm{~N}_{1.17}$ film annealed at $900{ }^{\circ} \mathrm{C}$ with b) corresponding selected area diffraction (SAED) pattern, and c) HRTEM detail image with narrow compositionally modulated layers indicated.

XRD shows no evidence of cubic or hexagonal AIN phases in any of the as-deposited films. Films with Ti content $1-x-y>0.34$ exhibit a fine-grained cubic structure. From the 002-peak broadening the average grain size is calculated to $7-15 \mathrm{~nm}$, using the Scherrer equation and the peak width as full width at half maximum (FWHM) [33].

The lattice parameter, $a_{0}$, was found to increase with increasing Ti content corresponding to a shift to smaller diffraction angles, in accordance with previous reports, see e.g. [34-36], and references therein. This effect is seen for all films, $0.34<1-\mathrm{x}-\mathrm{y} \leq 0.76$, where the fcc 002 peak position lies in the range $\sim 42.8-43.2^{\circ} 2 \theta$, corresponding to a lattice parameter of 4.19-4.22 $\AA$ as compared with $4.24 \AA$ for TiN [37] and $4.12 \AA$ for c-AlN [38].

The unit cell dimension, and hence the position 


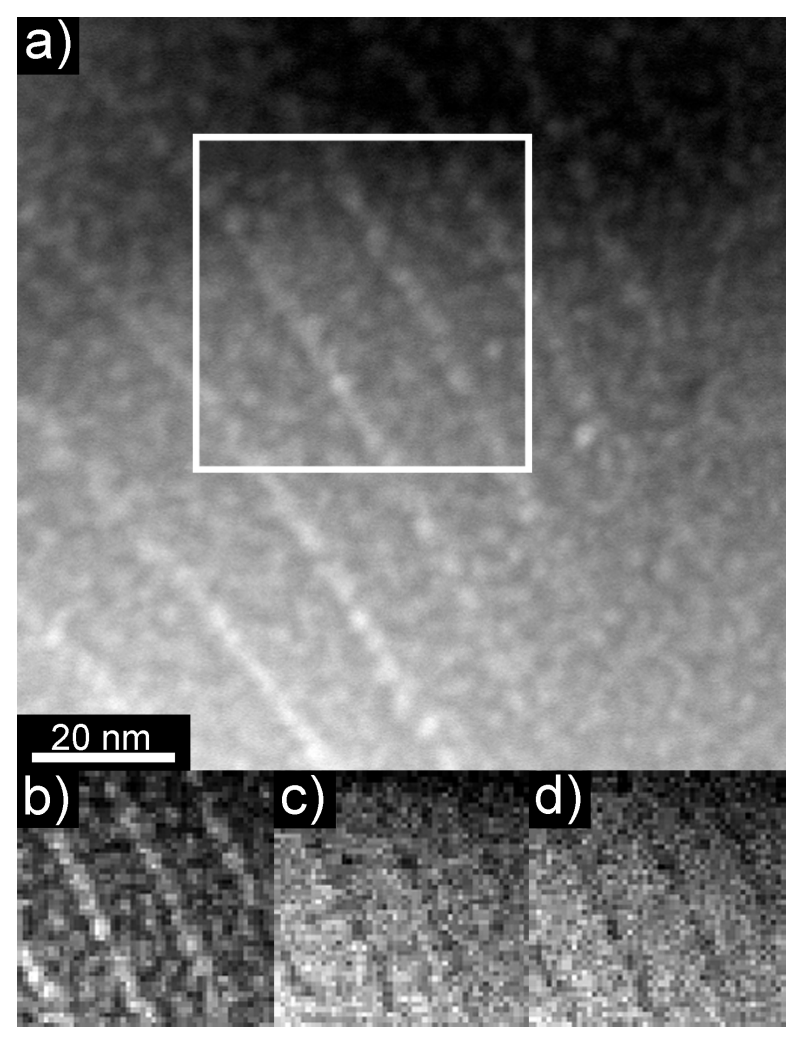

Figure 8: Cross-sectional a) STEM/HAADF image, and EDX elemental mapping, b) $\mathrm{Ti}$, c) $\mathrm{Al}$, d) $\mathrm{Si}$, of a $\mathrm{Ti}_{0.26} \mathrm{Al}_{0.46} \mathrm{Si}_{0.28} \mathrm{~N}_{1.17}$ film after annealing at $900{ }^{\circ} \mathrm{C}$.

of the diffraction peaks, are also affected by stresses in the film. Here, fcc 002 phases in films 1- $\mathrm{X}-$ $\mathrm{y}>0.34$ are under compressive stress, which ranges from $\sigma=-2.8 \pm 0.2 \mathrm{GPa}$ for the film with $\mathrm{Ti}$ content $1-\mathrm{x}-\mathrm{y}=0.58, \sigma=-3.8 \pm 0.7 \mathrm{GPa}$ with $1-\mathrm{x}-\mathrm{y}=0.62, \sigma=-$ $2.9 \pm 0.1 \mathrm{GPa}$ with $1-\mathrm{x}-\mathrm{y}=0.67$, and $\sigma=-5.1 \pm 0.7 \mathrm{GPa}$ with $1-\mathrm{x}-\mathrm{y}=0.76$.

The films containing larger amount of $\mathrm{Al}(\mathrm{x}=0.31$ and $\mathrm{x}=0.35$ films $)$ in combination with high Ti content (1$\mathrm{x}-\mathrm{y}>0.34)$ also show reflections of the fcc 111 peak. Increasing amounts of $\mathrm{Al}$ has previously been reported to change the preferred orientation from 002 to 111 in $\mathrm{Ti}_{1-x} \mathrm{Al}_{x} \mathrm{~N}$ films [23]. For (1-x-y>0.34) Si-rich films $(\mathrm{y}=0.22$ and $\mathrm{y}=0.25)$, the 002 reflection is significantly broader than for the films with $y=0.02$ and $y=0.07$, indicating a finer grain structure of the Si-rich films.

Fig. 3a) shows a cross-sectional TEM micrograph of the as-deposited $\mathrm{Ti}_{0.26} \mathrm{Al}_{0.46} \mathrm{Si}_{0.28} \mathrm{~N}_{1.17}$ film with corresponding selected area diffraction (SAED) pattern as inset. The film is homogeneous in nanostructure apart from droplets from the arc evaporation process. The film is mainly amorphous, but contains nanocrystallites

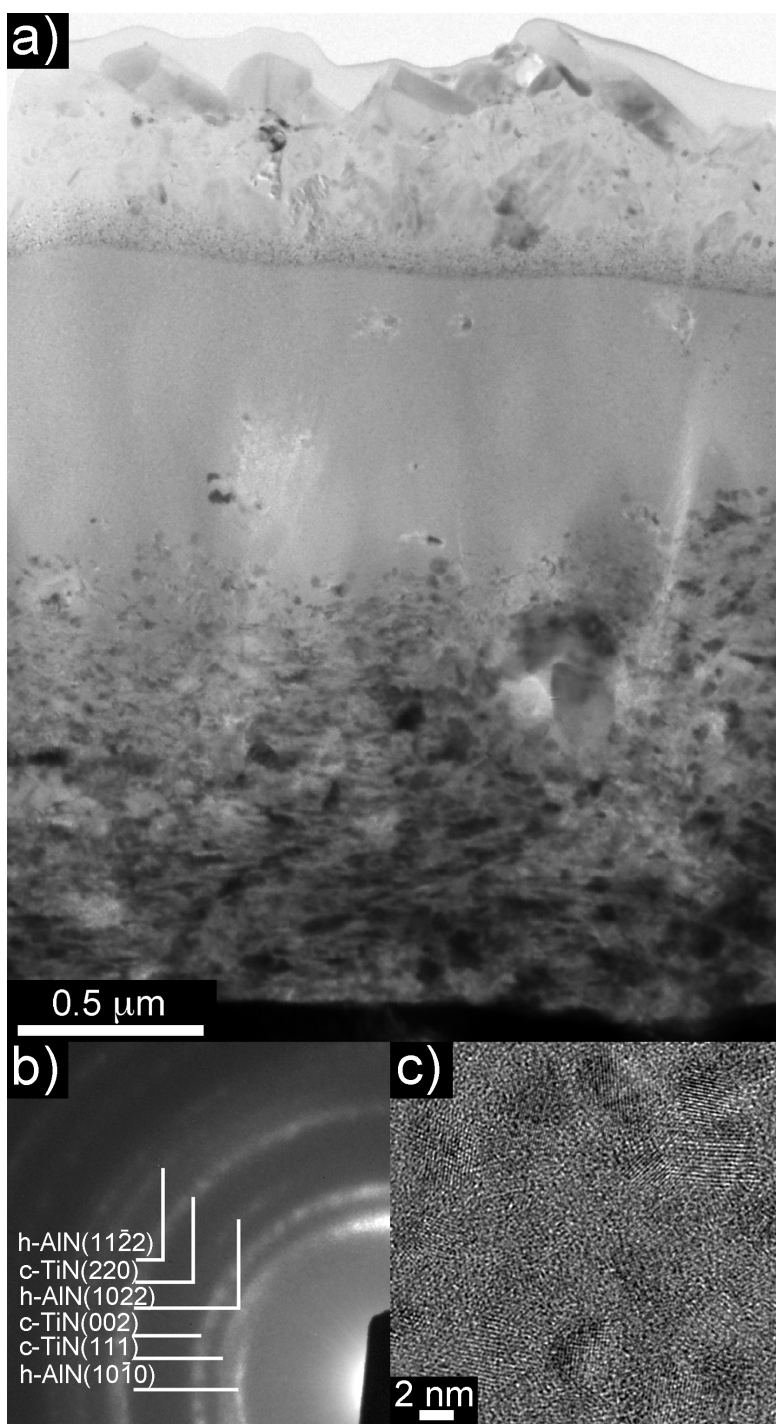

Figure 9: a) Cross-sectional overview of $\mathrm{Ti}_{0.26} \mathrm{Al}_{0.46} \mathrm{Si}_{0.28} \mathrm{~N}_{1.17}$ film annealed at $1100{ }^{\circ} \mathrm{C}$, b) corresponding selected area diffraction (SAED) pattern, and c) HRTEM detail image.

smaller than could be detected in XRD, i.e. X-ray amorphous. The HRTEM image in Fig. 3b) shows that the film initially grows epitaxial to the substrate over some 2-3 nm thickness, before amorphization. Fig. 3c), taken from an area $\sim 1 \mu \mathrm{m}$ up in the film where steady-state growth applies, reveal $\sim 2 \mathrm{~nm}$ crystallites of a cubic TiNlike phase. The crystallites are embedded in an amorphous matrix.

Fig. 4 shows the bright field images of the asdeposited $\mathrm{Ti}_{0.26} \mathrm{Al}_{0.46} \mathrm{Si}_{0.28} \mathrm{~N}_{1.17}$ film and corresponding inverse Fourier transform images at three different tilt angles, $\alpha=0^{\circ}$ ( $\mathrm{a}$ and b), $\alpha=10^{\circ}$ (c and d), and $\alpha=20^{\circ}$ (e and f), respectively. The tilt series was made in or- 
der to exclude that the amorphous matrix consists of nanocrystalline grains of different orientation. In some areas that initially appear amorphous, grains of size 3-4 $\mathrm{nm}$ display when tilting the sample (area A), while others disappear (area B), showing that the sample is partly nanocrystalline with randomly oriented grains. However, the major part of the amorphous matrix stays the same, and does not change regardless of tilt angle. This shows that the mainly amorphous films are essentially electron-diffraction amorphous, as the level of ordering in the amorphous matrix reaches the detection limit in TEM.

Results for nanoindentation and elastic modulus for as-deposited films are found in Fig. 5. The predominantly amorphous films, Ti content $1-\mathrm{x}-\mathrm{y} \leq 0.34$, have a hardness $19.4 \pm 0.5 \mathrm{GPa}$. For the crystalline films, there is an increase in hardness with increasing $\mathrm{Si}$ content up to $y=0.22$. This Si-related hardening effect has been reported in related ternary systems like Ti-Si-N [3], Zr-Si$\mathrm{N}$ [39], and Cr-Si-N [40] already at low concentrations $(\leq 10$ at $\%)$, where it is likely the result of solid-solution hardening in the crystalline films. The highest hardness, $34.7 \pm 1.0 \mathrm{GPa}$, is found for our film with $1-\mathrm{x}-\mathrm{y}=0.76$.

The result for the elastic modulus follows the same trend as for the hardness, where the elastic modulus values are significantly higher for nanocrystalline films (381-453 $\pm 9 \mathrm{GPa})$ than for amorphous ones (252$263 \pm 4 \mathrm{GPa}$ ). As the elastic modulus is a measure of a material's stiffness it is longer and/or weaker bonds in the amorphous films compared to the nanocrystalline films that is the explanation to the observed results. The bonding length, determined using SAED patterns, is $\sim 2.93 \AA$ for the as-deposited amorphous $\mathrm{Ti}_{0.26} \mathrm{Al}_{0.46} \mathrm{Si}_{0.28} \mathrm{~N}_{1.17}$ film. For the nanocrystalline films the bonding length was determined using the position of the 002 XRD peak position, and it was calculated to be 2.09-2.11 $\mathrm{A}$.

In order to investigate the thermal stability of the amorphous films, annealing experiments were performed on the $\mathrm{Ti}_{0.26} \mathrm{Al}_{0.46} \mathrm{Si}_{0.28} \mathrm{~N}_{1.17}$ film. The annealing temperature was between $500{ }^{\circ} \mathrm{C}$ and $1100{ }^{\circ} \mathrm{C}$. Room temperature ex-situ $\mathrm{x}$-ray diffraction of the films was performed in $\theta-2 \theta$ ranging from 30 to $70^{\circ} 2 \theta$. The results are presented in Fig. 6. There is no apparent change in the diffractograms up to $800{ }^{\circ} \mathrm{C}$. At $900{ }^{\circ} \mathrm{C}$ a broad peak is appearing between $39-46^{\circ} 2 \theta$, indicating that nanocrystals have formed in the film. When the temperature is further increased to $1000{ }^{\circ} \mathrm{C}$ the broad peak increases in intensity and a peak at $40.27^{\circ} 2 \theta$ corresponding to $\mathrm{W}$ is observed. At $1100{ }^{\circ} \mathrm{C}$ the TiN 111 and TiN 002 peaks are clearly visible, corresponding to crystallization of the film. In between the substrate peak at $36.06^{\circ} 2 \theta$ and the TiN 111 peak there is a peak showing up, partly covered by the substrate peak, that corresponds to h-AlN (0002). Also h-AlN (1010) is visible at $33.22^{\circ} 2 \theta$. Both are indicated in the figure by solid lines. Peaks originating from both $\mathrm{W}$ and Co are visible at $1100{ }^{\circ} \mathrm{C}$ showing that films annealed at the highest temperatures have been affected by out-diffusion of $\mathrm{Co}$ and $\mathrm{W}$ from the substrate, a phenomena that has been reported earlier for both $\mathrm{Ti}_{1-x} \mathrm{Al}_{x} \mathrm{~N}$ [4, 41] and $\mathrm{Ti}_{1-x} \mathrm{Si}_{x} \mathrm{~N}$ [3] films deposited under similar conditions, and is thoroughly described in Ref. [4].

Fig. 7a) shows a cross-sectional TEM micrograph of the $\mathrm{Ti}_{0.26} \mathrm{Al}_{0.46} \mathrm{Si}_{0.28} \mathrm{~N}_{1.17}$ film annealed at $900{ }^{\circ} \mathrm{C}$. Compared with the micrograph of the as-deposited film it is obvious that the homogeneous nanostructure of the film is intact. Nevertheless, the SAED pattern in Fig. 7b) indicates the growth of nanocrystals in the film, as could also be seen by XRD.

HRTEM in Fig. 7c) reveals that the initially $2 \mathrm{~nm}$ isolated crystallites have grown to $3-5 \mathrm{~nm}$ in size and are now contacting each other. There is also a layering in the film. The layering, also found in the as-deposited films (not shown), is due to compositional modulation resulting from the substrate rotation with respect to the fixed arc sources, as described by Eriksson et al. [42].

STEM/HAADF imaging and EDX elemental mapping of the film annealed at $900{ }^{\circ} \mathrm{C}$ in Fig. 8 show that the $\sim 3 \mathrm{~nm}$ nanocrystallite rich layers, seen in HRTEM in Fig. 7c), are enriched in Ti, see Fig. 8 a) and b), and that $\mathrm{Si}$ and $\mathrm{Al}$ are uniformly distributed over thicker $\sim 15$ nm layers, see Fig. 8c) and d).

Annealing at $1100{ }^{\circ} \mathrm{C}$ radically changes the nanostructure of the film. Fig. 9 shows the crosssectional overview a), and HRTEM image c), of the $\mathrm{Ti}_{0.26} \mathrm{Al}_{0.46} \mathrm{Si}_{0.28} \mathrm{~N}_{1.17}$ film annealed at $1100{ }^{\circ} \mathrm{C}$. Here, the layering is still present, see STEM/HAADF images in Fig. 10. At this temperature most of the film has crystallized into c-TiN and h-AlN, as is shown in the SAED in Fig. 9b). It is also obvious that the metals in the substrate have diffused into the film, as shown by the cross-sectional overview in Fig. 9a) and confirmed by the EDX elemental mapping shown in Fig. 10. The diffusion seems to start with Co-rich clusters that form in the film, visible as light grey dots in the film in Fig. 9a), and as bright areas in the STEM/HAADF image in Fig. 10e). After the Co-rich clusters have formed, $\mathrm{W}$ also starts to diffuse into the film, as seen by dark regions in the film in Fig. 9a). The artificial layering is retained in part even after the crystallization and outdiffusion of the substrate metals. Fig. 10c) and d) show that $\mathrm{Al}$ and $\mathrm{Si}$ remain evenly distributed throughout the film. An extensive oxide layer has formed on top of 


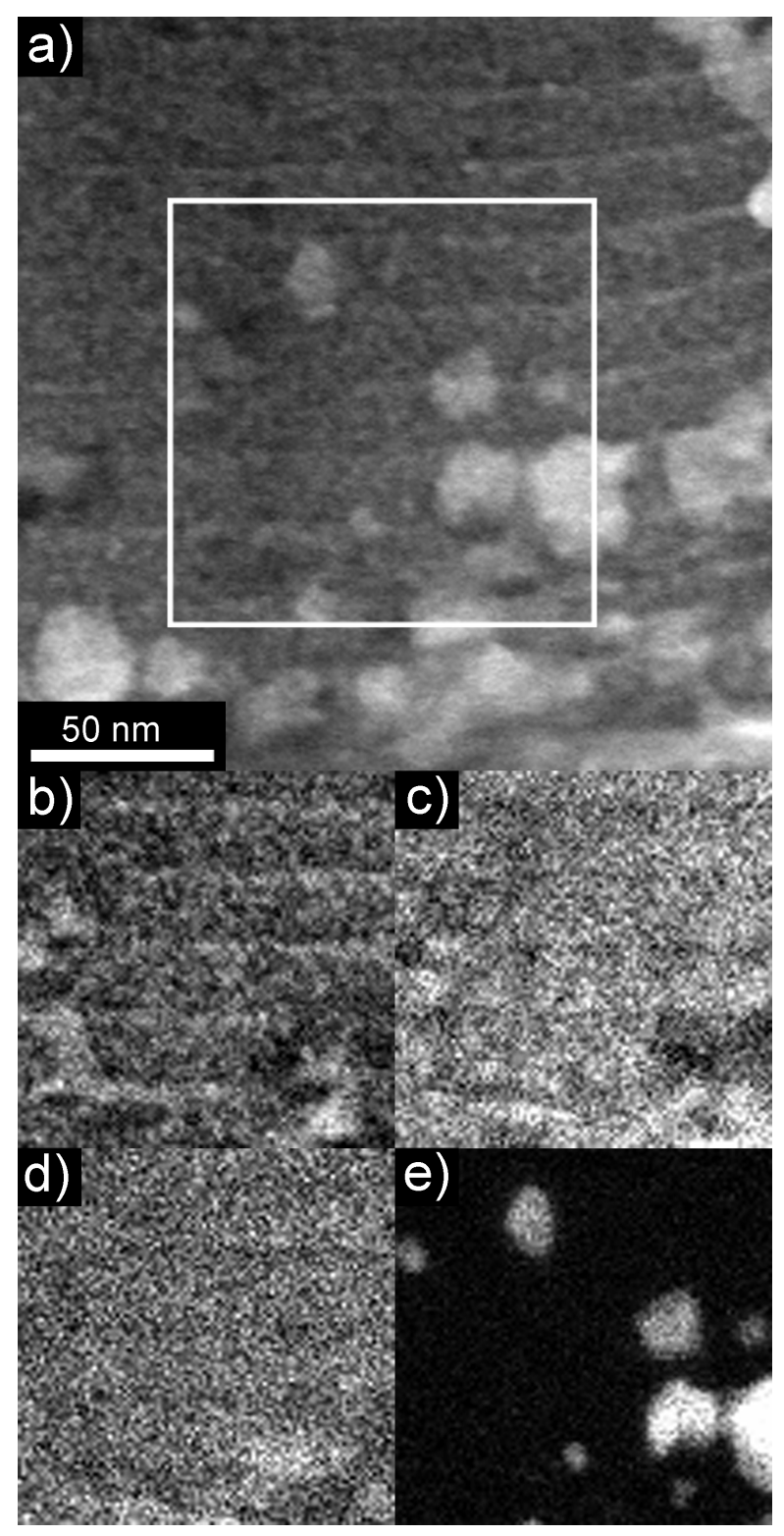

Figure 10: Cross-sectional a) STEM/HAADF image, and EDX elemental mapping, b) $\mathrm{Ti}$ c) $\mathrm{Al}$, d) $\mathrm{Si}$, and, e) $\mathrm{Co}$, of a $\mathrm{Ti}_{0.26} \mathrm{Al}_{0.46} \mathrm{Si}_{0.28} \mathrm{~N}_{1.17}$ film after annealing at $1100{ }^{\circ} \mathrm{C}$.

the film at $1100{ }^{\circ} \mathrm{C}$ as can be seen in Fig. 9a). This layer is $\sim 500 \mathrm{~nm}$ thick and mainly consists of oxides based on $\mathrm{Al}, \mathrm{Si}$, and $\mathrm{Ti}$, determined with EDX/TEM. A $\sim 100 \mathrm{~nm} \mathrm{TiO}{ }_{2}$ layer formed between the unreacted films and main top oxide layer. $\mathrm{W}$ is also present in both oxide layers.

Fig. 11 shows the hardness and elastic moduli measurements of the annealed $\mathrm{Ti}_{0.26} \mathrm{Al}_{0.46}$ Sibonding $_{0.28} \mathrm{~N}_{1.17}$ film performed by

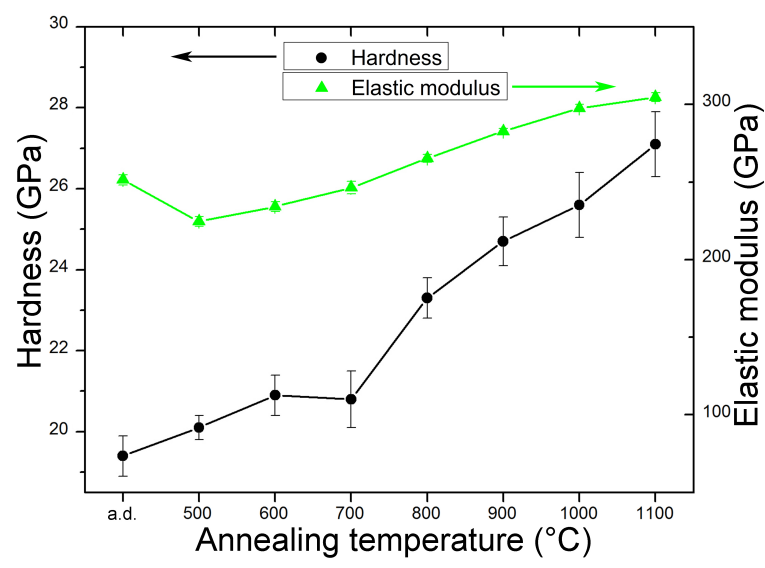

Figure 11: (Color online) Nanoindentation hardness (black circles) and elastic moduli (green triangles) of annealed $\mathrm{Ti}_{0.26} \mathrm{Al}_{0.46} \mathrm{Si}_{0.28} \mathrm{~N}_{1.17}$ films with respect to annealing temperature $500-1100{ }^{\circ} \mathrm{C}$

nanoindentation. There is an increase in hardness with increasing annealing temperature up to $1100{ }^{\circ} \mathrm{C}$, showing an apparent age hardening process. The increase in hardness is as high as $7.6 \mathrm{GPa}$, from $19.4 \pm 0.5 \mathrm{GPa}$ for the as-deposited film to $27.1 \pm 0.8 \mathrm{GPa}$ for the film annealed at $1100{ }^{\circ} \mathrm{C}$, which is attributed to a change from predominantly amorphous to nanocrystalline structure. The result for the elastic modulus follows the same trend as for the hardness, and show slightly increased values for increasing annealing temperature, explained by a decreased bonding lenght from $\sim 2.93 \AA$ for the as-deposited film to $\sim 2.68 \AA$ at $900{ }^{\circ} \mathrm{C}$ and $\sim 2.66 \AA$ at $1100{ }^{\circ} \mathrm{C}$. . This process leads to an increase of the elastic modulus of the film, from $252 \pm 2 \mathrm{GPa}$ to $305 \pm 2 \mathrm{GPa}$.

\section{Conclusions}

Hard amorphous Ti-Al-Si-N films were grown by arc evaporation. For a Ti content $\leq 0.34$, the films are predominantly amorphous with isolated few $2-3 \mathrm{~nm}$ crystallites, as determined by x-ray diffraction and electron diffraction. The films begin to crystallize at 900$1000{ }^{\circ} \mathrm{C}$ by coarsening of nanocrystallites, but with a size limit of 3-5 nm, preferentially in Ti-rich layers induced by substrate rotation. At $1100{ }^{\circ} \mathrm{C} \sim 1.5 \mu \mathrm{m}$ of the film thickness has crystallized with a growth front advancing from the substrate into an otherwise homogeneous material. The amorphous nitrides are hard in the as-deposited state and exhibit age hardening by 40 $\%$ up to $27.1 \mathrm{GPa}$, which is accompanied with a change from a mainly amorphous to a nanocrystalline state. 


\section{Acknowledgments}

This work was supported by the Swedish Government Strategic Research Area Grant (SFO MAT-LiU) on Advanced Functional Materials, the Swedish Research Council, and by the SSF-project Designed Multicomponent Coatings, MultiFilms.

[1] L. Shizhi, S. Yulong, P. Hongrui, Plasma Chemistry and Plasma Processing 12 (1992) 287-297.

[2] P. Hedenqvist, M. Bromark, M. Olsson, S. Högmark, E. Bergmann, Surface and Coatings Technology 63 (1994) 115122.

[3] A. Flink, T. Larsson, J. Sjölén, L. Karlsson, L. Hultman, Surface and Coatings Technology 200 (2005) 1535 - 1542

[4] A. Hörling, L. Hultman, M. Odén, J. Sjölén, L. Karlsson, Journal of Vacuum Science \& Technology A 20 (2002) 1815-1823.

[5] D. McIntyre, J. E. Greene, G. Håkansson, J.-E. Sundgren, W.-D. Münz, Journal of Applied Physics 67 (1990) 1542-1553.

[6] L. Donohue, I. Smith, W.-D. Münz, I. Petrov, J. Greene, Surface and Coatings Technology 94-95 (1997) 226- 231.

[7] A. Ingason, F. Magnus, J. Agustsson, S. Olafsson, J. Gudmundsson, Thin Solid Films 517 (2009) 6731 - 6736

[8] P. HolubárAa, M. Jílek, M. SímaAa, Surface and Coatings Technology 120-121 (1999) 184-188.

[9] C. Michaelsen, C. Gente, R. Bormann, Journal of Applied Physics 81 (1997) 6024-6030.

[10] H. Hecht, G. Weigang, S. Eickert, U. Geyer, Zeitschrift fur Physik B (1996).

[11] J. Musil, R. Daniel, P. Zeman, O. Takai, Thin Solid Films 478 (2005) $238-247$

[12] K. Hukari, R. Dannenberg, E. A. Stach, Journal of Materials Research 17 (2002) 550-555.

[13] X. Sun, J. S. Reid, E. Kolawa, M.-A. Nicolet, R. P. Ruiz, Journal of Applied Physics 81 (1997) 664-671.

[14] E. Blanquet, A.M. Dutron, V. Ghetta, C. Bernard, R. Madar, Microelectronic Engineering 37-38 (1997) 189 - 195.

[15] H.M. Benia, M. Guemmaz, G. Schmerber, A. Mosser, J.-C. Parlebas, Applied Surface Science 200 (2002) 231 - 238.

[16] R. Daniel, J. Musil, P. Zeman, C. Mitterer, Surface and Coatings Technology 201 (2006) 3368 - 3376.

[17] A. Flink, J. Andersson, B. Alling, R. Daniel, J. Sjölén, L. Karlsson, L. Hultman, Thin Solid Films 517 (2008) 714 - 721

[18] A. Flink, Growth and Characterization of Ti-Si-N Thin Films, Ph.D. thesis, Thin Film Physics, Linköping University, Sweden, 2008.

[19] Z. G. Li, Y. X. Wu, S. Miyake, Journal of Vacuum Science \& Technology A 25 (2007) 1524-1528.

[20] J. C. Slater, The Journal of Chemical Physics 41 (1964) 3199_ 3204.

[21] J.A. Sue, Surface and Coatings Technology 54-55 (1992) 154159.

[22] W. C. Oliver, G. M. Pharr, Journal of Materials Research 7 (1992) 1564-83.

[23] A. Hörling, Thermal stability and age hardening of TiN-based thin films, Ph.D. thesis, Thin Film Physics, Linköping University, Sweden, 2005.

[24] Alloy Phase Diagrams, ASM Handbook Online, 2002.

[25] A. Eriksson, Cathodic Arc Synthesis of Ti-Si-C-N Thin Films, Ph.D. thesis, Thin Film Physics, Linköping University, Sweden, 2012.

[26] A. Flink, M. Beckers, J. Sjölén, T. Larsson, S. Braun, L. Karlsson, L. Hultman, Journal of Materials Research 24 (2009) 2483 -2498 .
[27] C.-L. Chang, C.-T. Lin, P.-C. Tsai, W.-Y. Ho, D.-Y. Wang, Thin Solid Films 516 (2008) 5324 - 5329.

[28] S.-M. Yang, Y.-Y. Chang, D.-Y. Lin, D.-Y. Wang, W. Wu, Surface and Coatings Technology 202 (2008) $2176-2181$.

[29] S. Veprek, S. Reiprich, L. Shizhi, Applied Physics Letters 66 (1995) 2640 - 2642.

[30] E.V. Shalaeva, S.V. Borisov, O.F. Denisov, M.V. Kuznetsov, Thin Solid Films 339 (1999) 129 - 136.

[31] J.-E. Sundgren, B. O. Johansson, A. Rockett, S. A. Barnett, J. E. Greene, Americal Institute of Physics Series 149, 1986.

[32] P. H. Mayrhofer, C. Mitterer, H. Clemens, Advanced Engineering Materials 7 (2005) 1071-1082.

[33] H.P. Klug, L.E. Alexander, X-ray Diffraction Procedures: For Polycrystalline and Amorphous Materials, Wiley, New York, 1974.

[34] H. A. Jehn, S. Hofmann, V.-E. Rückborn, W.-D. Münz, Journal of Vacuum Science \& Technology A 4 (1986) 2701-2705.

[35] O. Knotek, M. Böhmer, T. Leyendecker, Journal of Vacuum Science \& Technology A 4 (1986) 2695-2700.

[36] P. Mayrhofer, C. Mitterer, L. Hultman, H. Clemens, Progress in Materials Science 51 (2006) 1032-1114.

[37] TiN, Powder Diffraction File c-TiN: 38-1420, JCPDS International Centre for Diffraction Data, Swarthmore, PA, 1998.

[38] AlN, Powder Diffraction File c-AlN: 25-1495, JCPDS International Centre for Diffraction Data, Swarthmore, PA, 1998.

[39] P.J. Martin, A. Bendavid, J.M. Cairney, M. Hoffman, Surface and Coatings Technology 200 (2005) 2228 - 2235.

[40] J. H. Park, W. S. Chung, Y.-R. Cho, K. H. Kim, Surface and Coatings Technology 188-189 (2004) 425 - 430.

[41] A. Hörling, L. Hultman, M. Odén, J. Sjölén, L. Karlsson, Surface and Coatings Technology 191 (2005) 384-392.

[42] A. Eriksson, J. Zhu, N. Ghafoor, M. Johansson, J. Sjölén, J. Jensen, M. Odén, L. Hultman, J. Rosén, Surface and Coatings Technology 205 (2011) 3923-3930. 